\title{
Development and Implementation of a Voltage Real-Time Monitor System of Electrical Network with Remote Access
}

\author{
G. P. Colnago ${ }^{1}$, J. L. F. Vieira ${ }^{1}$, G. C. D. Sousa ${ }^{1}$, E. Trabach ${ }^{2}$, J. R. Macedo ${ }^{3}$ and L. B. B. Macieira ${ }^{3}$ \\ ${ }^{1}$ Department of Electrical Engineering \\ C.T., Federal University of Espitiro Santo \\ Campus of Goiabeiras - Goiabeiras, 514 Vitoria (Brazil)
}

Phone/Fax number:+55 274009 2644, e-mail: guilhermecolnago@gmail.com, joseluiz@ele.ufes.br, g.sousa@ele.ufes.br

${ }^{2}$ FEST

Av. Fernando Ferrarri - Goiabeiras, 845 - Vitória (Brazil)

Phone/Fax number: +55 274009 2181, e-mail: emerson.trarbach@gmail.com

${ }^{3}$ EDP ESCELSA

Rod. BR-101 Norte - Carapina, 3450 Serra (Brazil)

Phone/Fax number: +55 273348 4206, e-mail: jrmacedo@edpbr.com.br, leonardo.macieira@enbr.com.br

\begin{abstract}
.
This paper discusses the development and implementation of a digital power quality meter to comply with the new standard which will regulate the Power Quality in Brazil. Its main objective has been to become a low cost device capable of monitoring the main Power Quality indices of the new standard, such as the steady state RMS voltage, harmonic distortion, voltage fluctuation, voltage unbalance, voltage sags and swells, as well as power supply interruptions in real-time. Through a cellular GPRS module, the meter can be remotely controlled and configured. In this way, it can exchange measurements and information data with a remote server, thus constituting a Power Quality monitoring system.
\end{abstract}

\section{Key words}

Voltage monitoring, power quality, power supply interruption, remote access.

\section{Introduction}

The Brazilian Electrical Energy Agency (ANEEL) promulgated in 2008 a standard to regulate the electric distribution in the country [1]. A chapter of the standard is dedicated to Power Quality (PQ), area which was never regulated before. This chapter defines the procedures and computations of PQ indices, describes the electrical disturbances of interest, and defines the quality indices and reference values - some of them have not been defined yet.

The standard foresees a period for a national campaign to collect and analyze the data and propose new quality indices and reference values.

In Brazil it was found three types of equipment for power quality measurement. A low cost one, which does not satisfy the new standard [2]. Two others, of medium and high cost, are likely to satisfy the new standard, but are too expensive for large scale utilization. In this paper, it is presented a low cost device, which satisfy the main points of the new standard and it is cost effective for large scale use [3].

\section{The Brazilian Power Quality Standard}

The PQ chapter is divided in quality of product and quality of service. The indices of quality of service are related with power supply interruptions; the indices of quality of product are related mainly to voltage. They are:
1) Steady State RMS Voltage;
2) Power Factor:
3) Harmonics;
4) Voltage Unbalence;
5) Voltage Fluctuation;
6) Voltage Sags and Swells;
7) Frequency Variation.

In Brazil there use to be no regulations on PQ area. As the new standard includes phenomena never regulated before, some indices do not have well defined reference values (and procedures for final computation). As a consequence, the standard manifests great interest on monitoring of phenomena such as harmonics, voltage unbalance, voltage fluctuation, voltage sags and swells, since the results of these indices will be used to determine the future reference values.

\section{Power Quality Meter Overview}

The market evaluation has permitted to observe that devices which satisfy the standard have cost above a thousand US dollars. One purpose of the development of the device meter (DM) is to have low cost (in the range of a few hundred US dollars).

To achieve this goal, the current measurement (necessary for power factor computation) was suppressed. On a three phase system, such measurement requires three 
high precision current transformers, which constitutes relatively high cost components. It has been observed that several devices meters in the national market have a high cost due the current transformers. Therefore, it was defined that just the most important indices should be monitored to reduce the meter cost.

The monitored indices are: steady state RMS voltage, voltage harmonics, voltage fluctuation, voltage unbalance, voltage sags and swells, and power supply interruptions.

An overview of developed DM is shown in Fig. 1, which presents the general block diagram of the device. The DM is connected to the electrical network, and monitors the voltage supplied to the consumers.

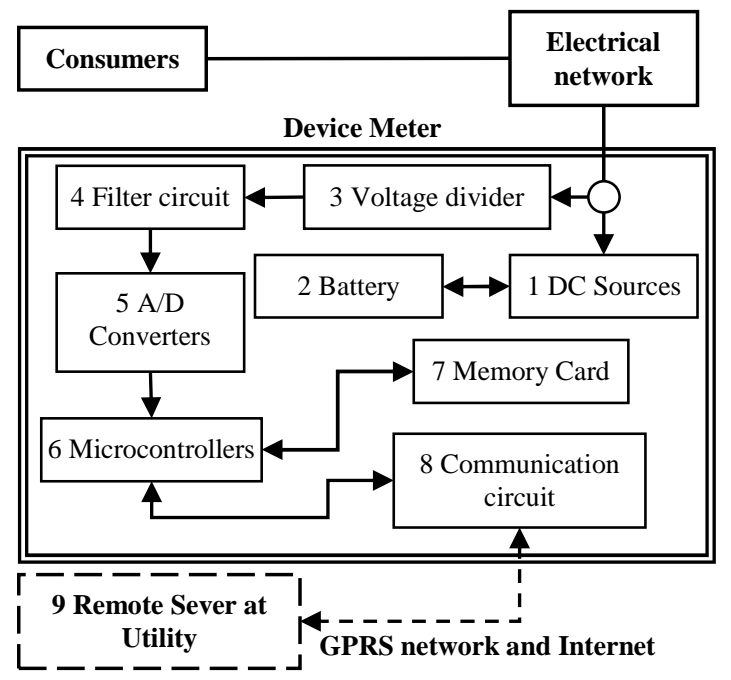

Fig. 1. Device meter's general block diagram.

The DM is formed by eight basic blocks:

1. DC Sources: it is formed by DC sources supplied by the electrical network;

2. Battery: it is formed by rechargeable battery (to supply the DM on power supply interruptions) and a circuit to recharge the battery;

3. Voltage divider: it is formed by a set of three circuits (one for each phase) that reduces the voltage levels to values under $5 \mathrm{~V}$ and converts the AC signals to DC;

4. Filter circuit: it is formed by three sets of active filter circuits. Its function is to remove the high frequencies from the spectrum, and prevent aliasing effects;

5. A/D Converters: it is formed by a set of three 12 bit A/D converters. They digitalize the filtered signals to the microcontroller;

6. Microcontrollers: two low cost microcontrollers form this block. One of them processes the signals and the indices in real-time; the other one manages the system, records the results, and communicates with the remote server (transferring data and measurements);

7. Memory Card: it is a non-volatile memory card (flash memory). It stores the measured data for posterior transmission. If necessary, the card allows the user downloads locally the measured data.

8. Communication circuit: it is formed by a cellular GPRS module. It provides the communication between DM and the remote server by the GPRS network and Internet.

The diagram presents a ninth block. It does not belong to the DM, but it is part of the PQ monitoring system. It is a remote server at the utility company, which is responsible for the communication with all the DMs through the Internet and GPRS networks. It configures and downloads the measured data from the DMs remotely. After the installation, no local work is necessary and the DMs can be fully remotely controlled.

\section{A. Technical Specification}

The DM was developed to monitor three phase systems of grounded star type with frequency and phase voltage equal to $60 \mathrm{~Hz}$ and $127 \mathrm{~V} \pm 25 \%$, very common values in Brazil. In agreement with the standard, the DM has 12 bits resolution A/D converters, accuracy of $1 \%$ on voltage measurement, and monitors up to the $25^{\text {th }}$ harmonic voltage component.

Due its flexibility, the DM can monitor electrical networks of different nominal voltage. For this purpose is necessary to use a set of potential transformers to convert the desired voltage to a base voltage of $127 \mathrm{~V}$. After this, it is just necessary to configure a multiplier factor on the applicative software, and all generated reports will be converted from $127 \mathrm{~V}$ base voltage to the original voltage.

\section{B. Hardware Description}

The power supply circuit of the DM is formed by one transformer per phase. They reduce the voltage level of the electrical network to supply the DC sources. Each secondary winding has a bridge rectifier. The reduced and rectified voltages are connected to a single node such that, if there is enough voltage in at least one phase, the system will be normally supplied by the electric network. If a general outage occurs, a relay is commutated, and the battery begins to supply the DM (the battery can supply the system for some hours). This is necessary because the standard requires that the data continues to be monitored during interruptions.

The signal processing system is formed by analog and digital circuits. The voltage divider and filter circuits form the analog part; the digital part is formed by $\mathrm{A} / \mathrm{D}$ converters and the microcontroller.

The analog part performs a direct voltage level reduction with resistive dividers (without electrical isolation) and operational amplifiers (OpAmps). In this way, there is a cost reduction and the elimination of a source of possible signal distortions. The OpAmps perform an offset sum on the reduced signals, to convert them from AC type to DC type, required by the $\mathrm{A} / \mathrm{D}$ input. 
The filter stage utilizes an $8^{\text {th }}$ order Butterworth low-pass filter of Sallen-Key type topology. This kind of filter was chosen because it presents a flat pass-band without ripple distortion, and unity gain. The topology has tolerance to low variation on component values, and it is very simple to be implemented with OpAmps.

The sample rate chosen was 128 samples per electrical network cycles $(7.68 \mathrm{kHz})$, and it is higher than the required minimum value of 16 samples/cycle of the standard. As the DM has to monitor up to $25^{\text {th }}$ harmonic component $(1.5 \mathrm{kHz})$ the cut-off frequency was defined as $1.8 \mathrm{kHz}$. Therefore this filter will have attenuation higher than the $52 \mathrm{~dB}$ on the half of the sample rate $(3.48 \mathrm{kHz})$, thus satisfying the Nyquist-Shannon Sampling Theorem, and eliminating the aliasing effect.

On the digital part the filtered signals are sampled and converted to digital values by $\mathrm{A} / \mathrm{D}$ converters at resolution of 12 bits. The digital signals are sent to a low cost signal processor. The processor is a microcontroller of dsPIC33f family, from Microchip. It has a modified Harvard architecture and it is a RISC processor with hardware modules for signal processing (common on DSPs).

The last part of the DM is completely digital, formed by a memory card circuit, cellular module circuit and the other microcontroller. The second microcontroller manages the DM. It record measurement on the memory card and communicates with the remote server by the cellular module. The cellular operates on the GSM network (very common in Brazil). To accomplish the communication it uses the GPRS network and Internet and just need to know the IP address of the remote server (this is a configurable parameter).

The Remote Server is a server computer that supervises and commands the set of DMs. It receives the measurement results (and other data) and maintains a data base of all measurements. This data base is available to system's users by a developed applicative. This applicative software produces reports and presents the results in the format of spread sheets, graphs and so on.

\section{Power Quality Indices Computation}

The measurement procedure is performed in agreement with the above mentioned standard. Some indices, however, present just a partial methodology of computation, which lacks the guidelines of how to compute the final indices. In these cases, additional procedures were defined by the development group - in the future, the new standard will likely be modified and these questions will be properly addressed.

Each phase has its own registers to store the voltage measurements. The measurement is accomplished in time intervals that are measured continuously. The measurement is done for a one week period (7 days or 168 hours). This period is divided in a set of 1,008 intervals of 10 minutes. Each interval is the integration of a set of 3,000 time "windows". Each window contains 12 electrical network cycles (or $0,2 \mathrm{~ms}$ ). The basic sample rating is 128 samples/cycle $(7.68 \mathrm{kHz})$. For several indices, this rate is excessive, and a lower sampling rate is utilized. This does not affect the accuracy of the results, and reduces the processing burden.

\section{A. Power Supply Interruption}

A power supply interruption is characterized when the RMS voltage value of one or more phases is below $0.1 \mathrm{pu}$ continuously for a minimum time interval of 3 minutes. The end of interruption occurs when all the phase RMS voltages rise above $0.1 \mathrm{pu}$. The interrupt register is recorded, and contains information about the affected phases, the beginning and the ending time of the occurrence, and the duration time.

The intervals affected by interruptions must be invalidated. Invalid intervals are registered, but they are not used on steady state analyses. The number of invalid intervals has to be replaced by equal number of valid subsequent intervals and the final measurement has to have 1,008 valid intervals. So, it is possible that a measurement has a time span greater than one week ( 7 days).

\section{B. Steady State RMS Voltage}

The steady state RMS voltage is calculated with the integration of the 3,000 time windows of $0,2 \mathrm{~s}$, resulting in the computation of RMS voltage value for each 10 minute intervals. For this index, the sampling rate is 64 samples/cycle (an undersampling).

For each 10 minute interval is registered the overall RMS voltage, the maximum and minimum RMS voltage from the $0,2 \mathrm{~s}$ windows of the interval. The RMS voltage values are analyzed and statistically distributed on voltage ranges labeled "adequate", "precarious" and "critic". In this index (as well as in the others) the invalid intervals have to be replaced by an equal number of subsequent valid intervals.

\section{Harmonics}

The standard requires the harmonic processing up to $25^{\text {th }}$ component (at least). The sampling rate is 128 samples/cycle. Specifically for this index, the 10 minutes interval contains 4,500 time windows. In this case the time window is formed by 8 line cycles that implies in a total of 1,024 samples per window. This number is multiple of $2^{\mathrm{n}}$ and allows the use of Fast Fourier Transform (FFT), what optimizes the processing.

For each window 24 harmonics components are processed (from the $2^{\text {nd }}$ up to the $25^{\text {th }}$ ) and the total harmonic distortion. Unlike the RMS voltage, the standard does not specify a global final index, therefore it was defined that the maximum computed values on interval each 10 minute interval would be recorded. So the maximum percentage value of Total Harmonic Distortion (THD\%) and the maximum percentage value of each " $h$ " order Individual Harmonic Distortion 
$\left(\mathrm{IHD}_{\mathrm{h}} \%\right)$ are registered. The $\mathrm{THD} \%$ and $\mathrm{IHD}_{\mathrm{h}} \%$ values are computed by equations (1) and (2), respectively.

$$
\begin{gathered}
I H D_{h} \%=\frac{V_{h}}{V_{1}} \cdot 100 \\
T H D \%=\frac{\sqrt{\sum_{h=2}^{25} V_{h}^{2}}}{V_{1}} \cdot 100
\end{gathered}
$$

where:

$\mathrm{V}_{1}$ : voltage of the fundamental component $(60 \mathrm{~Hz})$;

$\mathrm{V}_{\mathrm{h}}$ : voltage of the "h" order harmonic component.

\section{Voltage Unbalance}

The processing of voltage unbalance is done through CIGRE equation, where the voltage line values are used to compute the Voltage Unbalance Factor (VUF\%), in percentage, according to equations (3) and (4). The sampling rate employed is 64 samples/cycle.

$$
V U F \%=100 \cdot \sqrt{\frac{1-\sqrt{3-6 \beta}}{1+\sqrt{3-6 \beta}}}
$$

where:

$$
\beta=\frac{V_{a b}^{4}+V_{b c}^{4}+V_{c a}^{4}}{\left(V_{a b}{ }^{2}+V_{b c}{ }^{2}+V_{c a}^{2}\right)^{2}}
$$

and $\mathrm{V}_{\mathrm{ab}}, \mathrm{V}_{\mathrm{bc}}$ and $\mathrm{V}_{\mathrm{ca}}$ are the line RMS voltages.

As the standard does not define how to compute the final index, it was defined that for each interval, the average VUF, and the maximum VUF of the interval windows would be recorded.

\section{E. Voltage Sags and Swells}

The voltage sag and swell are defined by the Brazilian standard as transient phenomenon called "Short Time Voltage Variation" (STVV). When the RMS voltage is below 0.9pu the STVV is defined as voltage sag; when the RMS voltage is above $1.1 \mathrm{pu}$ the STVV is defined as voltage swell. The STVV is just determined and registered if the event has a duration that varies between 1 line cycle (about $16,67 \mathrm{~ms}$ ) up to 3 minutes. Out of this range, it is not classified as a transient phenomenon, it is considered as a deviation of steady state RMS voltage. The sampling rate for this index is 64 samples/cycle.

The recorded registers have the beginning and the ending time of the event, the worst absolute voltage value measured (occurred in the observed cycles), the duration time and the affected phase. In case of concurrent events, all the affected phases are registered, and the phase with the most severe voltage variation. The end of the event is determined when all the phases go back to normal state. As voltage sags and swells are different phenomena, they are registered separately, even in concurrent events.

The Fig. 2 shows how the voltage sags, swells and power supply interruption are defined. A voltage swell is defined when the RMS voltages is above $1.1 \mathrm{pu}$ on a time interval $\mathrm{T} 1$ corresponding to some network cycles; a voltage sag is defined when the RMS voltages is below $0.9 \mathrm{pu}$ on a time interval $\mathrm{T} 2$ corresponding to some cycles; and the interruption is defined when the RMS voltages is bellow $0.1 \mathrm{pu}$ on a time interval $\mathrm{T} 3$ greater than 3 minutes.

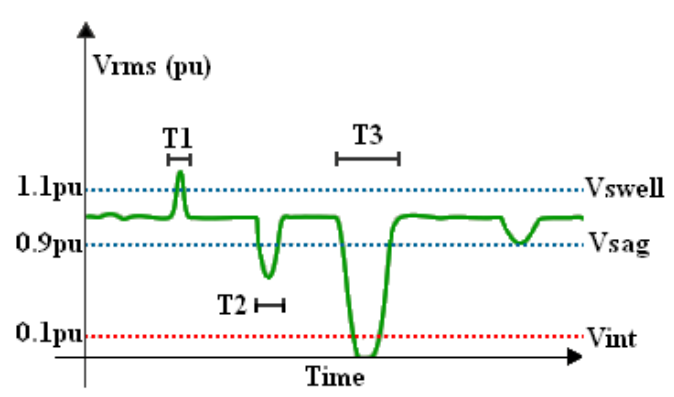

Fig. 2. RMS Voltage $x$ Time graph.

\section{F. Voltage Fluctuation}

The processing of this index is based on an adaption of the flickermeter model of IEC standard 61000-4-15 [4]. The first block of the model was substituted for the divider and filter circuit of the DM. However, the part that scales the mean RMS value is digitally done in the signal processor. All the posterior filter blocks were digitalized. As there is a high processing demand, the sampling rate was reduced to 16 samples/cycle $(960 \mathrm{~Hz})$, the minimum sampling rate allowed by the Brazilian standard. With this rate was possible to validate the adapted flickermeter model in agreement with test protocol of IEC standard [4]. The last block, the statistical, performs the computation of short-term flicker severity of interval, the Pst, given by equation (5). To reduce the processing effort, the block utilizes just 128 classes, and a simple linear classification for flicker evaluation.

$$
P s t=\sqrt{0,0314 P_{0,1}+0,0525 P_{1 S}+0,0657 P_{3 S}+0,28 P_{10 S}+0,08 P_{50 S}}(5)
$$
where:

$P_{i}$ (percentile $i$ ): is the flicker level exceeded for " $i$ " $\%$ of the time during the observation period. The "S" suffix indicates that smoothed value is used.

At the end of measurement of all intervals, the results are sent to the remote server, in which the computation of the long-term flicker severity (Plt) is performed. The Plt is derived from a set of Psts occurred on a period of 2 hours, in agreement with the equation (6). Others indices are computed daily and weekly from the Pst and Plt values.

$$
P l t=\sqrt[3]{\frac{1}{N} \sum_{i=1}^{N}\left(P s t_{i}\right)^{3}}
$$

where:

Pst $t_{\mathrm{i}}$ : is the Pst of the interval " $\mathrm{i}$ ";

$\mathrm{N}$ : the number of Psts that completes a period of 2 hours.

The DM was developed to have flexibility on the measurements, so the period of a measurement can be configured to 1,3 or 7 days, with intervals of $1,5,10$ or 15 minutes - in this case the number of windows changes in agreement with the duration of the interval. 


\section{Results and Performance Analysis}

A set of tests was performed to verify the performance of the DM. To evaluate the sensibility of the DM to occurrences of interruptions and STVV, several disturbances were generated. All of them were registered, and the records of their duration, values, start and ending times, and affected phases were assessed as correct.

Firstly, for the voltage fluctuation index, it was performed requested tests by the protocol of IEC standard [4] to validate the flickermeter algorithm. After the DM was validated, several comparative measurements were performed with a second, calibrated, device meter to verify the performance of the proposed DM. The "Power Sentinel GPS-Synchronized 1133A" of the Arbiter System (and a Class A device meter) was used as device meter of admeasurement (DMA). The Table I shows a set of results. It presents records of Pst to a voltage fluctuation of 110 changes/minute and about $0.85 \%$ of modulation. The values recorded by the devices meters are on the $2^{\text {nd }}$ and $3^{\text {rd }}$ column; the last column shows the relative error between the DM and the DMA.

Table I. - Comparative Pst results.

\begin{tabular}{|c|c|c|c|}
\cline { 2 - 3 } \multicolumn{1}{c|}{} & \multicolumn{2}{c|}{ Pst (pu) } & \multicolumn{1}{c}{} \\
\hline Time & $1133 \mathrm{~A}$ & Device meter & Relative Error \\
\hline 10:50 & 1,091520 & 1,074424 & $\mathbf{1 , 5 7 \%}$ \\
\hline 11:00 & 1,092991 & 1,075492 & $\mathbf{1 , 6 0 \%}$ \\
\hline $11: 10$ & 1,089046 & 1,072647 & $\mathbf{1 , 5 1 \%}$ \\
\hline
\end{tabular}

To test the performance of steady state RMS voltage and harmonics results, a power function generator was used, the "Chroma - Programmable AC Source - Model 6512" of the Chroma ATE Inc. It allows the user to configure the RMS voltage value, frequency and the shape of the signal. It produces a set of distorted voltage signals with pre-defined harmonic components. Several signals were used on the tests. One of them, called DST10, is shown in Fig. 3.

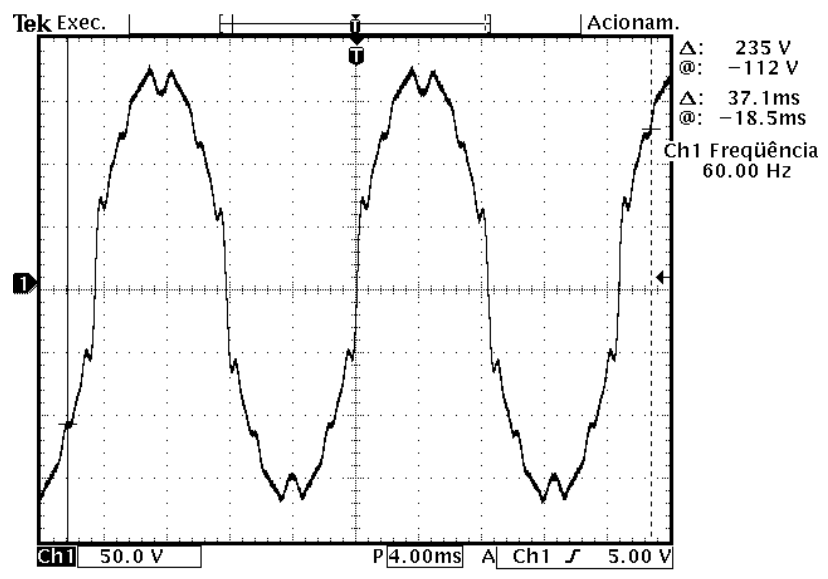

Fig. 3. Distorted voltage signal DST10.

The RMS voltage of this signal was configured to $127 \mathrm{~V}$ and the fundamental frequency to $60 \mathrm{~Hz}$. The DMA used was the high accuracy device meter "Portable Power
Sentinel 933A" of Arbiter System. The Table II shows the results. The $1^{\text {st }}$ column informs which results are presented (RMS voltage, THD and IHD); the $2^{\text {nd }}$ and $3^{\text {rd }}$ columns present the results of DM and DMA, respectively; and the $4^{\text {th }}$ column presents the spectrum (theoretical) produced by the source. The results were read from LCD's of devices meters - because the DMA has a different computation and register methodology to record the harmonic data. In this way, it was possible to observe the instantaneous values of the harmonics, in percentage. The generated signal is formed by all the odd harmonic components from the $3^{\text {rd }}$ up to the $25^{\text {th }}$ (highlighted in the table) - it can be observed that the source also generates even harmonic components.

Table II. - Voltage and Harmonics results of DST10 signal.

\begin{tabular}{|c|c|c|c|}
\cline { 2 - 3 } \multicolumn{1}{c|}{} & $\begin{array}{c}\text { Device } \\
\text { Meter }\end{array}$ & $\begin{array}{c}\text { 933A } \\
\text { Meter }\end{array}$ & \multirow{2}{*}{ Spectrum } \\
Vrms (V) & 126,86 & 126,9516 & Source \\
\hline THD (\%) & 13,35 & 13,38 & \\
\hline \multicolumn{3}{|c|}{ Harmonics components } \\
\hline h2 (\%) & 0,21 & 0,20 & - \\
\hline h3 (\%) & 9,80 & 9,82 & 9,80 \\
\hline h4 (\%) & 0,10 & 0,11 & - \\
\hline h5 (\%) & 3,21 & 3,21 & 3,20 \\
\hline h6 (\%) & 0,03 & 0,02 & - \\
\hline h7 (\%) & 5,44 & 5,42 & 5,40 \\
\hline h8 (\%) & 0,09 & 0,09 & - \\
\hline h9 (\%) & 1,22 & 1,21 & 1,20 \\
\hline h10 (\%) & 0,00 & 0,00 & - \\
\hline h11 (\%) & 2,84 & 2,83 & 2,80 \\
\hline h12(\%) & 0,04 & 0,04 & - \\
\hline h13 (\%) & 1,43 & 1,42 & 1,40 \\
\hline h14 (\%) & 0,04 & 0,04 & - \\
\hline h15 (\%) & 4,09 & 4,07 & 4,00 \\
\hline h16 (\%) & 0,10 & 0,09 & - \\
\hline h17 (\%) & 2,26 & 2,26 & 2,20 \\
\hline h18 (\%) & 0,10 & 0,10 & - \\
\hline h19 (\%) & 1,45 & 1,45 & 1,40 \\
\hline h20 (\%) & 0,09 & 0,07 & - \\
\hline h21 (\%) & 1,45 & 1,45 & 1,40 \\
\hline h22 (\%) & 0,08 & 0,07 & - \\
\hline h23 (\%) & 1,65 & 1,67 & 1,60 \\
\hline h24 (\%) & 0,12 & 0,12 & - \\
\hline h25 (\%) & 1,42 & 1,47 & 1,40 \\
\hline & & & \\
\hline
\end{tabular}

A comparative result about the voltage unbalance index is shown in Table III. It was done measurements of 1 minute intervals from an unbalanced three phase system with $127 \mathrm{~V}$ nominal phase voltage. The used DMA was the 933A. The DM records the average value of the voltage unbalance factor. The DMA records the values of the positive, negative and zero voltage sequences. Therefore, to compute the VUF of DMA, it was necessary to use equation (7):

$$
V U F \%=100 \cdot \frac{V_{-}}{V_{+}}
$$

where:

$\mathrm{V}_{+}$and $\mathrm{V}$ : : positive and negative voltage sequence, respectively. 
Table III. - Voltage Unbalance results.

\begin{tabular}{|c|c|c|}
\cline { 2 - 3 } \multicolumn{1}{c|}{} & \multicolumn{2}{c|}{ Voltage Unbalance Factor $(\%)$} \\
\hline Time & Device Meter & 933A Meter \\
\hline $17: 50$ & 1,04 & 1,05 \\
\hline $17: 51$ & 1,03 & 1,05 \\
\hline $17: 52$ & 1,00 & 1,00 \\
\hline $17: 53$ & 0,89 & 0,88 \\
\hline $17: 54$ & 0,81 & 0,80 \\
\hline
\end{tabular}

\section{A. Final Version of the Device Meter}

Fig. 4 shows the final version of the PQ device meter. In the picture, the letter " $A$ " indicates the main printed circuit board (PCB) that has the signal processing circuit and the digital circuits (communication, memory, etc); " $\mathrm{B}$ " indicates the power supply PCB that contain the DC sources and all the protection of the device; "C" indicates the antenna of cellular module; and " $\mathrm{D}$ " indicates the external cable to connect the device to the electrical network.

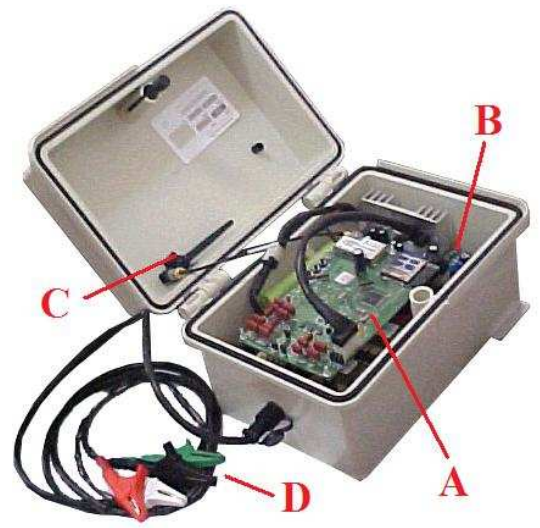

Fig. 4. Final Version of the Device Meter.

\section{Conclusion}

The proposed DM presented satisfactory results, and it can be said that it has achieved the main requirements of the Brazilian standard. Its simplified hardware allowed achieving its objective of low cost, and it is a viable candidate to become a commercial product.

The contribution of this work and its product, the DM, is to allow the possibility to introduce in the Brazilian market, a device meter of low cost for the national measurement campaign, and with the advantage that it can be controlled and monitored remotely. Several units of the DM were delivered to the local electric utility company, which sponsored the research, to be tested for a long term period for further validation.

\section{Acknowledgement}

This work was financed by Energias de Portugal-Espirito Santo Centrais Eletricas SA (EDP ESCELSA), and is a result of a Research \& Development project, implemented as a joint effort of the EDP ESCELSA, The Federal University of Espirito Santo (UFES) and ANEEL.
The authors would like to thank the EDP ESCELSA for the financial and technical support, in particular, for allowing them to use its high accuracy device meters to analyze and verify the performance of the developed device meter.

\section{References}

[1] ANEEL, Procedimento de Distribuição de Energia Elétrica PRODIST, Módulo 8, ANEEL, Brazil (2008), pp. 1-53.

[2] J. R. Carvalho, et al, "Desenvolvimento de um Instrumento para Monitoração de Energia", In Citinel - II Congresso de Inovação Tecnológica em Energia Elétrica 2003, pp. 872-874.

[3] G. P. Colnago, "Desenvolvimento e Implementação de um Sistema de Monitoramento em Tempo Real da Tensão da Rede com Acesso Remoto", Master degree thesis in Power Quality, Department of Electrical Engineering, UFES, Vitoria (2009), pp. 18-141.

[4] IEC, CEI/IEC 61000-4-15: 1997 + A1: 2003: Part 4: Testing and measurement techniques - Section 15: Flickermeter, Geneva (2003), Edition 1.1, pp. 1-47.

[5] M. H. J. Bollen and I. Y. H. Gu, Signal Processing Of Power Quality Disturbances, John Wiley \& Sons, New York (2006), pp. 1-276.

[6] M. Piekars, et al, "Comparative Tests of Flickermeters", In 10th International Conference on Harmonics and Quality of Power 2002, Vol. 1, pp. 220-227.

[7] J. Ruiz, et al, "Analysis of Sensitivity to the main parameters involved in the digital implementation of the UIE Flickermeter", In 10th Mediterranean Electrotechnical Conference 2000, Vol. 2, pp. 823-826.

[8] D. Gallo, et al, "Implementations of a Test System for Advanced Calibration and Performance Analysis of Flickermeters", In IEEE Transactions on Instrumentation and Measurement 2004, Vol. 53, Number 4, pp.1078-1085.

[9] E. Gunther, "Harmonic and Interharmonic Measurement According to IEEE 519 and IEC 61000-4-7", In IEEE PES Transmission and Distribution Conference and Exhibition 2006, pp. 223-225.

[10] J. P. S. Rocha and S. M. Deckman, "Digital Flickermeter Implementation", In 38th MWSCAS 1995, Vol. 2, pp. 757-760. [11] M. Mazadi and S. H. Hosseinian, "Flickermeter Simulation to Use in Power System Analysis Software", In 39th International Universities Power Engineering Conference 2004, Vol. 1, pp. 917-923.

[12] IEC, CEI/IEC 61000-4-7: Testing and measurement techniques - General guide on harmonics and interharmonics measurements and instrumentation, for power supply systems and equipment connected thereto, Genveva (2002), Edition 2, pp. 11-69.

[13] IEEE, IEEE 519 - Recommended Practices and Requirements for Harmonic Control in Electric Power Systems, New York (2008), Draft 3, pp. 5-18.

[14] L. Marques, E. Araújo and J. A. S. Brito, "Registrador de Qualidade da Tensão com Leitura Remota", In Citinel - II Congresso de Inovação Tecnológica em Energia Elétrica, 2003. p. 913-915.

[15] J. Middlehurst, Practical Filter Design, Prentice-Hall, Australia (1993), pp. 35-117.

[16] A. V. Oppenheim and A. S. Willsky, Signals and Systems, Prentice Hall, Englewood cliffs (1975), pp. 7-573.

[17] W. J. F. Lima, et al, "Desenvolvimento do Protótipo de um Instrumento Virtual para Análise On-line de Perturbações Harmônicas em Sistemas de Potência", In Citinel - II Congresso de Inovação Tecnológica em Energia Elétrica 2003, pp. $875-878$. 